\title{
Dissolution of Gelatin Capsules: Evidence and Confirmation of Cross-Linking
}

\section{ABSTRACT}

Cross-linking is a common problem in the dissolution of gelatin capsules. Cross-linking is characterized by a bridge across the peptide backbone of the gelatin molecule which creates water insoluble membranes or pellicles during dissolution testing. The chemical covalent bonding between gelatin chains is typically triggered by catalytic amounts of aldehyde and/or from exposure to high temperature and humidity. Cross-linking gelatin capsules results in a slower release of the drug or no release at all in common dissolution media. If the gelatin capsule dissolution fails acceptance criteria due to evidence of cross-linking, the US Pharmacopeia allows the use of enzymes in the dissolution medium and requires twotier dissolution testing. Studies have shown that drugs from cross-linked capsules are available in vivo to the patient, justifying the use of enzymes in the in vitro dissolution test. The literature contains several examples supporting evidence of cross-linking. However, confirming the degree of cross-linking continues to be a practical challenge due to a lack of quantitative procedures for measuring the extent of cross-linking and variability in options for formulations, excipients, level and types of stresses, and the experience level of the analysts. This article reviews the methodologies to confirm the evidence of cross-linking such as visual observation, capsule shell switch test, and spectroscopic determination of cross-linking, with an aim to facilitate the discussion and establishment of an acceptable standard approach.

KEYWORDS: Gelatin capsule, dissolution, gelatin cross-linking, cross-linking identification, spectroscopic evidence of cross-linking

\section{INTRODUCTION}

ross-linking is a common problem for solid oral dosage formulations filling hard gelatin capsules (HGC) and soft gelatin capsules (SGC), as well as for gelatin-coated tablets. Cross-linking directly impacts the capsule product during in vitro dissolution drug release testing, resulting in slower or incomplete release of the drug or no release at all. The USP General Chapters Dissolution <711> (1) and Disintegration and Dissolution of Dietary Supplements <2040> (2) allow the addition of enzymes to the dissolution medium when the dosage forms do not conform to the dissolution acceptance criteria due to gelatin cross-linking. Recent revisions in these two USP chapters (which became official on May 1 , 2016) further addressed current challenges regarding enzyme use in the dissolution medium and provided new recommendations to overcome the challenges associated with the use of enzymes (3). The recommendations covered three aspects. First, they speak to the choice of enzymes that may be used based on the $\mathrm{pH}$ of the dissolution medium, recommending pepsin for $\mathrm{pH}$ equal to or below 4.0, papain or bromelain for $\mathrm{pH}$ above 4.0 and below 6.8 , and pancreatin for $\mathrm{pH}$ equal to or above 6.8 .
Secondly, they state both the enzyme activity and amount to be added to the medium should be determined. Thirdly, they indicate a pre-treatment procedure should be used when the dissolution medium contains a surfactant or any other ingredient known to denature the enzyme in use. Figure 1 shows the workflow and decision tree for gelatin capsule dissolution based on the USP general chapter $<711>$ (1).

Before following the USP recommendations to use enzymes for the dissolution of cross-linked gelatin capsules, it is important to confirm evidence of crosslinking as the cause of a dissolution run failing to meet the expected acceptance criteria. The recently revised USP $<711>$ (1) provides guidance on this, stating that, "because of evidence of the presence of cross-linking, the dissolution procedure should be repeated with the addition of enzymes to the medium." This clarifies the older version of USP $<711>$ chapter (4) that did not exclusively link gelatin capsule dissolution failure to the presence of cross-linking in the gelatin. This lack of clarity may have led an analyst to assume that enzymes could be used for any failure, even those not related to gelatin cross-linking. This misunderstanding could be problematic

*Corresponding author. 


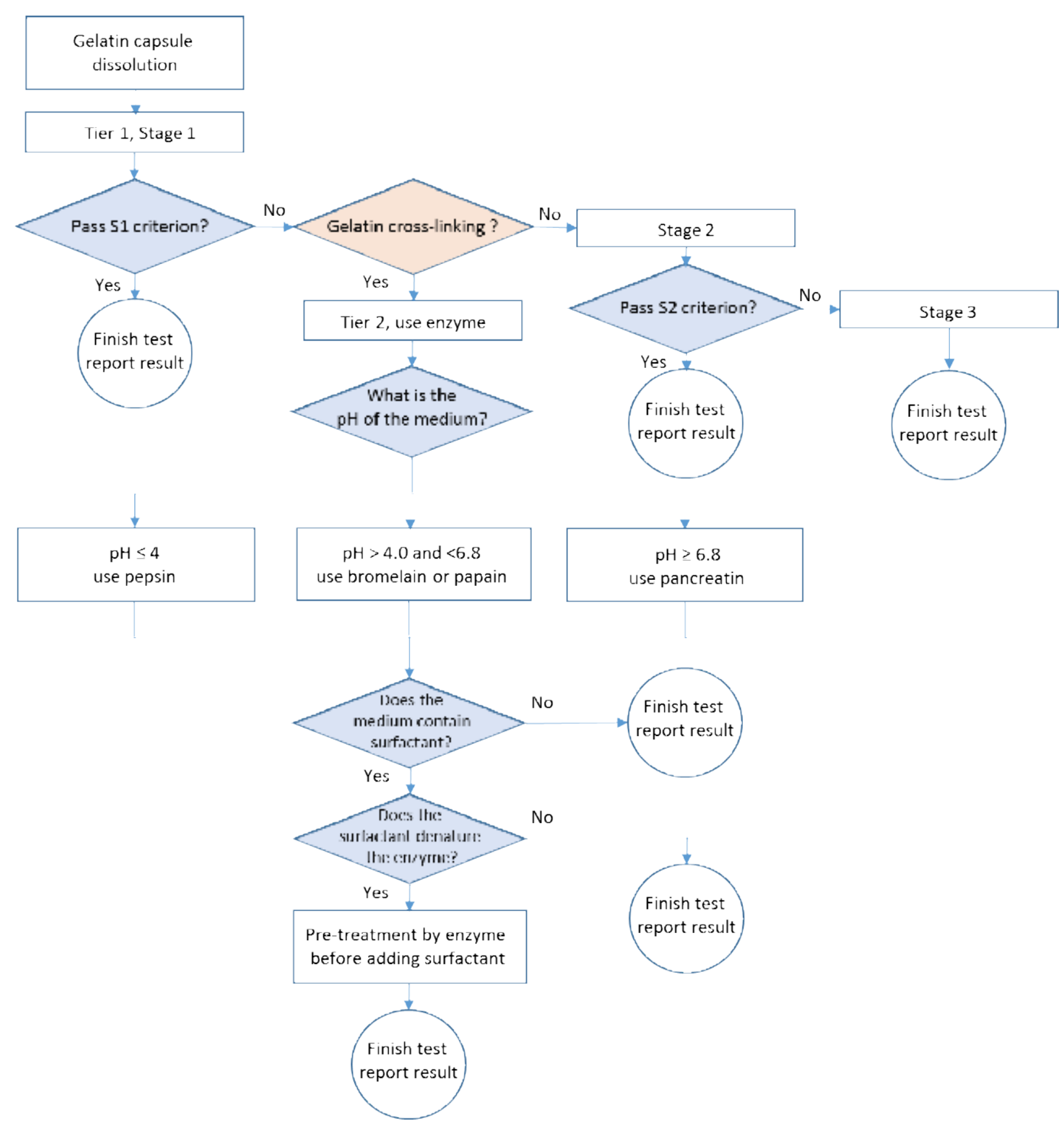

Figure 1. A flowchartof gelatin capsule dissolution based on USP $<711>$. $^{a}$

${ }^{a}<711>$ Dissolution. In The United States Pharmacopedia and National Formulary USP 37-NF 32; 2014 (1).

for justifying enzyme use for quality control release or stability dissolution testing. Although the recently revised USP $<711>$ provided much-needed clarification on gelatin cross-linking related dissolution failure, it still omits the importance of clarification on how the evidence of the cross-linking is documented, and what constitutes sufficient documentation and justification practices for the use of an enzyme, especially for testing Good
Manufacturing Practice (GMP) samples, that is, marketed product stability samples and/or clinical re-assay samples once they fail to meet the in vitro dissolution acceptance criteria. This article reviews the literature describing evidence of cross-linking and methodologies to confirm gelatin cross-linking. A brief overview of the background of gelatin capsule cross-linking and the history of related studies is followed by a discussion on the use of evidence, 
methodologies for confirmation, and the possibility of establishing an acceptable regulatory procedure regarding this justification.

\section{BRIEF OVERVIEW OF GELATIN CAPSULE}

\section{CROSS-LINKING AND RELATED STUDIES}

Gelatin is a mixture of amino acids and peptides derived from collagen through hydrolysis $(5,6)$. Gelatin crosslinking occurs due to chemical reactions between the amino acids or peptide chains of gelatin. The most common type of reaction involves the amine group of a lysine and a similar amine group on a neighbor molecule and forms a strong covalent bond. The reactions can be triggered by trace level of aldehydes present in excipients or the active pharmaceutical ingredient (API), or because of the degradation of any component of the formulation or packaging material. It also can occur under certain stressed conditions, such as high temperature and humidity. Once the cross-linking starts, it does not stop even when the cause is removed.

Cross-linking and Impact to Gelatin Capsule Dissolution Changes affecting the in vitro dissolution of gelatin capsules due to exposure to high humidity conditions were reported as early as the 1970s (7-9). More comprehensive studies were conducted in the 1980s (10-15) including observations for both HGC and SGC that cross-linking alters the physiochemical properties of the gelatin capsule shells and generate a water-insoluble film or pellicle around the gelatin capsule shell, on the inside or outside surfaces, or both. The dissolution rates of the capsule formulations were significantly retarded when the cross-linking occurred (16). A review article by Digenis et al. in 1994 (17) examined the mechanistic rationalizations of gelatin cross-linking under conditions that are relevant to pharmaceutical conditions and summarized the chemistry of gelatin cross-linking under elevated temperature and high humidity conditions, as well as the chemical interactions between gelatin and aldehyde.

While the impact of cross-linking on the dissolution of gelatin capsules attracted much attention, many efforts have been made to understand the relevance of the in vitro dissolution of cross-linked gelatin capsules to their in vivo performance (17-20). Studies were conducted to determine the effect of prolonged storage conditions on the bioavailability and clinical efficacy of drugs in gelatin capsules. Cases were also reported in which the bioavailability of the drug from the stressed capsules did not significantly alter in vivo performance when compared to freshly prepared capsules (10, 20-23). A comparison of the in vitro dissolution rate of drug release from stressed gelatin capsules with their in vivo performance has been reported (5).

\section{Establishment of Two-tier Dissolution Test}

Extensive studies have been conducted to determine if gastrointestinal tract enzymes, including pepsin and pancreatin, could digest the cross-linked gelatin and overcome the adverse effect on capsule dissolution and, in turn, drug release. Results confirmed the slower drug release noted in in vitro dissolution due to stressful storage conditions of gelatin capsules, such as high humidity and temperatures and severe light, were virtually eliminated when the products were tested in dissolution media containing enzymes $(24,25)$. Based on these findings, a recommendation was made to include enzymes in the USP test medium for the special evaluation of aged gelatin capsules (26) in in vitro dissolution testing.

A US Food and Drug Administration/Industry Gelatin Capsule Working Group was formed in the early 1990s to conduct a full investigation on the noncompliance of gelatin capsules during in vitro dissolution tests and the potential changes in bioavailability $(27,28)$. HGCs and SGCs were carefully stressed to different levels and compared with unstressed capsules to determine the relationship between in vitro and in vivo performance. The proper level of the enzyme was determined that could discriminate between bioequivalent and bio-inequivalent capsules. The results were used to establish the amount of enzymes that could be added to the dissolution medium for a second dissolution test of the capsules that failed to pass the first dissolution test due to the presence of cross-linking in the gelatin. A two-tier dissolution test was included in the First Supplement to USP 24 (4). An excellent review by Singh et al. summarized the problem of the alteration in the dissolution characteristics of gelatinbased formulations due to cross-linking, examined the established cause, mechanisms, influencing factors, and stress methods for a study of the behavior, and described the reported solutions to the problem including the use of enzymes for the second tier dissolution test (29).

Since the establishment of the USP two-tier dissolution test, it has been possible to follow a standard procedure for handling cross-linked gelatin capsules. The time and cost of previously required bioequivalence studies have been saved. However, various studies continue in this field, including studies to prevent capsule crosslinking by incorporating glycine and citric acid into the capsule formulation (6), studies to establish a correlation between the concentration of formaldehyde and the reduction in dissolution of gelatin capsules (30), studies 
to investigate the influence of excipient composition on granulation characteristics and pellicle formation inside gelatin capsules (31), studies to explore the challenges in liquid and semisolid filled gelatin capsules (32), and studies to determine the disintegration and changes in in vitro drug release from cross-linked HGCs containing water-insoluble drugs $(33,34)$.

\section{Enzyme Activity and Performance for}

Cross-linked Gelatin Capsule Dissolution

One area attracting a high level of interest was evaluating the enzyme activity and the digestive performance ability of the enzymes added into the dissolution medium for the Tier-2 test $(35,36)$. The use of enzymes in a medium containing surfactant can be problematic. Surfactants are frequently used to improve the solubility of poorly soluble drugs in dissolution; the activity of the enzymes can be affected by the surfactant, especially when an anionic surfactant is involved like sodium lauryl sulfate (SLS). In dissolution experiments with moderately stressed HGCS containing a water-insoluble drug in both simulated gastric fluid (SGF) and simulated intestinal fluid with enzymes and $2 \%$ SLS, no drug release occurred despite the presence of pepsin or pancreatin in the medium (35). In another study, SLS significantly reduced the dissolution of gelatin capsules below $\mathrm{pH} 5$ because the SLS interacted with the gelatin shells and formed a precipitate that was less soluble (37). When the activities of pepsin and pancreatin were examined in the presence of a different surfactant, Tween 80, far better disintegration and dissolution were observed compared to SLS use (38). In a recent study, the activity of pepsin was investigated with different types of surfactants in SGF in concentrations above and below their critical micellar concentrations. A significant reduction in the activity of pepsin was reported in the presence of SLS at all the concentrations tested. On the contrary, the pepsin activity was not altered by use of cetyltrimethyl ammonium bromide (CTAB), Tween 80 , or Triton X100 at any of the concentrations tested (39).

To overcome the effect of the surfactants on enzymatic activity, the USP Tier-2 dissolution test has been studied in two steps $(40,41)$. In the first step, the cross-linked gelatin capsules are pretreated for a short time using the medium containing the enzyme but without the surfactant. In the second step, a solution containing the surfactant is added to the dissolution vessel to make the final concentration of the surfactant in the vessel align with the method requirements. The pretreatment procedure has been included in the USP $<711>$ (1).

In the early version of USP <711> (4), pepsin was recommended for use in water or medium with a $\mathrm{pH}$ less than 6.8 , and pancreatin was recommended for use in medium with $\mathrm{pH}$ equal to or greater than 6.8 (42). The literature indicates pepsin has good protease activity up to a $\mathrm{pH}$ of 4 . There is a need to identify the appropriate enzymes that could be used in dissolution media that have $\mathrm{pH}$ in the range from 4 to 6.8. Papain and bromelain have been selected for this purpose. Since these two enzymes are not found in the human body, their application is not intended to mimic any in vivo behavior. Both enzymes can effectively digest the cross-linked gelatin in dissolution media in the $\mathrm{pH}$ range from 4 to $7(3,43-44)$.

\section{EVIDENCE OF CROSS-LINKING IN CAPSULE DISSOLUTION}

Since 2000, the USP has allowed two-tier dissolution testing when the dosage form containing gelatin does not meet the dissolution specification in the first stage (4). In 2015, the USP general chapter $<711>$ was revised, which emphasized that to proceed to the second stage of testing with the addition of enzymes to the medium, the cause of the failure in the first stage has to be confirmed as cross-linking in the gelatin (1). Therefore, following the USP $<711>$ new requirements, it is important to confirm and document the evidence of gelatin capsule cross-linking. We will focus on the methodologies considered for confirming gelatin capsule cross-linking as the cause of dissolution slowdown. These methodologies can be categorized into three types: (1) visual observation, (2) capsule switching test, and (3) spectroscopic determination.

\section{Visual Observation}

Visual observation is an important part of dissolution testing (45). It can provide valuable information regarding how a solid dosage tablet or capsule product disintegrates, how the drug is released, and any capsule shell cross-linking-related phenomena. However, it is appropriate to expect situations or cases in which the analyst may not pay attention to visual observations. Although numerous articles reported the decreased drug release and distorted dissolution profiles for gelatin capsules under stresses such as high temperature, high humidity, strong light, and formaldehyde treatment, only a handful of cases reported in the literature described the phenomena related to gelatin capsule cross-linking during dissolution testing (see Table 1).

A detail description of the evidence of gelatin capsule cross-linking was stated in USP <1094> (47): "A pellicle is a thin, water-insoluble clear membrane of cross-linked protein on the inner or outer surface of the capsule that prevents the capsule fill from being released. Cross-linking is evidenced byathin membraneoragelatinousmass noted 
Table 1. Visual Observations on Gelatin Capsule Cross-linking Reported in the Literature* (Cases Describing Observed Cross-linking Are Limited)

\begin{tabular}{|c|c|c|c|c|c|}
\hline \multirow{2}{*}{ Dosage Form } & \multicolumn{3}{|c|}{ Storage conditions } & \multirow{2}{*}{ Effect on dissolution } & \multirow{2}{*}{ Visual observation } \\
\hline & Temp. ${ }^{\circ} \mathrm{C}$ & \%RH & Time & & \\
\hline \multicolumn{6}{|l|}{ Hard gelatin capsules: } \\
\hline \multirow{3}{*}{ Chloramphenicol $^{a}$} & 25 & 49,66 & 32 weeks & $\begin{array}{l}\text { No change in drug } \\
\text { release }\end{array}$ & No apparent change in disintegration. \\
\hline & 25 & 80 & 32 weeks & No release till 1 hour & Gelatin shell failed to disintegrate. \\
\hline & 25 & 100 & 32 weeks & No release & $\begin{array}{l}\text { Gelatin shells were rubbery, soft, and difficult to } \\
\text { handle. }\end{array}$ \\
\hline Gemfibrozil $^{b}$ & 37 & 80 & $\begin{array}{l}1,2 \text {, and } \\
3 \text { months }\end{array}$ & $\begin{array}{l}\text { Significant decrease at } \\
1 \text { month }\end{array}$ & Film formation after 1 month \\
\hline \multirow{3}{*}{$\begin{array}{r}\text { Hydrophobic drug } \\
\text { in various colored } \\
\text { capsules }^{c}\end{array}$} & 25 & 80 & $\begin{array}{l}\text { Ambient light, } \\
2 \text { weeks }\end{array}$ & Significant decrease & $\begin{array}{l}\text { Swelled within minutes and formed a poorly } \\
\text { disintegrating elastic matrix after } 12-15 \text { min. into } \\
\text { the test. }\end{array}$ \\
\hline & 30 & 80 & $\begin{array}{l}\text { Fluorescent, } \\
2 \text { weeks }\end{array}$ & Significant decrease & $\begin{array}{l}\text { The aged capsules swelled and formed a partially } \\
\text { insoluble gelatin shell. A swollen, rubbery gelatin } \\
\text { matrix, which enveloped the encapsulated powder, } \\
\text { was noted during the dissolution. }\end{array}$ \\
\hline & 27 & 80 & UV, 2 days & Significant decrease & Formed insoluble film. \\
\hline Gemfibrozi $(E)^{d}$ & 40 & 85 & $4,8,12$ weeks & NA & $\begin{array}{l}\text { Increase in disintegration time and evidence of } \\
\text { gelatin cross-linking was prevalent. }\end{array}$ \\
\hline Piroxicam $(\mathrm{G})^{d}$ & 40 & 85 & $4,8,12$ weeks & NA & $\begin{array}{l}\text { Dramatic increase in disintegration time. Pellicle } \\
\text { formation was observed in all tested capsules. }\end{array}$ \\
\hline $\begin{array}{r}\text { Development API } \\
\text { with lactose-based } \\
\text { granules }^{e}\end{array}$ & 40 & 75 & 12 weeks & Significant decrease & $\begin{array}{l}\text { Noticeable pellicle formation (a palpable gel-like } \\
\text { colorless film) inside capsules. }\end{array}$ \\
\hline Org $12962^{f}$ & 40 & 75 & $\begin{array}{l}1,3,4,5,6 \\
14 \text { months }\end{array}$ & NA & Slower disintegration after 6 months. \\
\hline Erlotinib $^{g}$ & 40 & 75 & 4 weeks & Significant decrease & $\begin{array}{l}\text { Not fully disintegrated at } 15 \mathrm{~min} . \text {, with lump form } \\
\text { covered by a gel-like film at } 45 \mathrm{~min} \text {. }\end{array}$ \\
\hline $\begin{array}{r}\text { Genentech } \\
\text { development drug }\end{array}$ & 40 & 75 & $\begin{array}{l}1 \text { and } \\
3 \text { months }\end{array}$ & $\begin{array}{l}\text { Significant decrease } \\
\text { and variation }\end{array}$ & $\begin{array}{l}\text { After } 3 \text { months, capsule disintegrated slowly. Some } \\
\text { capsules appeared to be gelling with blend trapped } \\
\text { inside, not ruptured until "infinity" at } 250 \mathrm{rpm} \text {. }\end{array}$ \\
\hline \multicolumn{6}{|l|}{ Soft gelatin capsules: } \\
\hline $\begin{array}{r}\text { Medium-chain } \\
\text { triglycerides in } \mathrm{SGC}^{i}\end{array}$ & 60 & NA & 2-6 weeks & Significant decrease & $\begin{array}{l}\text { Maintained a swollen state for } 30 \mathrm{~min} \text {. and varied } \\
\text { into insoluble shell }\end{array}$ \\
\hline
\end{tabular}

*Adapted from Table VI in Singh et al. (29) with additions of a column of “Visual observation" and new cases.

${ }^{a}$ Khalil, et al. Pharmazie. 1974, 29, 36-37 (8).

${ }^{b}$ Chafetz, et al. J. Pharm. Sci. 1984, 73 (8), 1186-1187 (11).

'Murthy, et al. Pharm. Technol. 1989, 13 (3), 72-84 (14).

${ }^{d}$ Adesunloye, et al. Drug Dev. Ind. Pharm. 1998, 24 (6), 493-500 (6).

${ }^{e}$ Chang, et al. AAPS PharmSciTech. 2008; 9 (2), 597-604 (31).

fPennings, et al. Drug Dev. Ind. Pharm. 2006, 32, 33-37 (38).

${ }^{9}$ Lu, et al. J. Pharm. Biomed. Anal. 2011, 56, 23-29 (40).

${ }^{h}$ Cui, et al. Pharm. Technol. 2011, 35 (5), 62-68 (41).

'Hakata, et al. Chem. Pharm. Bull. 1994, 42, 1496-1500 (22).

Abbreviations: API, active pharmaceutical ingredient; NA, not applicable; RH, relative humidity; SGC, soft gel capsules.

during dissolution testing." However, before USP <1094> was published, gelatin capsule cross-linking phenomena, linked to decreased drug release, were described in several different ways (Table 1). The most frequent observation is a significant increase in disintegration time $(8,11,38,40$, 41). The other observations are the formation of a gellike film $(11,14,31,40)$, swollen, rubbery elastic matrix $(8,14,22)$, or gelling with embedded drug blend (41). The differences in the reported descriptions might be due to the different experiences of the analysts who performed the dissolution testing. The differences in observation may be related to the different levels of cross-linking from different stressed conditions and due to the variability and inhomogeneity of cross-linking. Although the pellicle itself may be difficult to observe (46), noticeable pellicle formation has been reported in more than one study $(30,31)$. 
Keeping a written record of visual observations has been a typical practice. However, pictures and videos have been increasingly used in modern laboratories for capturing observations of dissolution testing. Specially designed video cameras can also be installed next to the dissolution vessel to record the entire dissolution event. Pictures can be taken at specific time points to see the disintegration of the dosage form, dispersion of particulates, and gelatin cross-linking effects. Figure 2 (a) and (b) shows pellicles from cross-linked gelatin capsules in USP apparatus 1 and $2(3,44)$. The capsules are hydrated and swollen but not ruptured. The thin membrane or gelatinous masses can be seen around the capsules; these masses enveloped the encapsulated powder and hindered drug release. The authors did not indicate whether these were taken from heavily stressed gelatin capsule samples. The formation of a pellicle in most situations may not be so obvious, especially for those moderately or lightly stressed gelatin capsules and those from stability studies when cross-linking starts to form and just starts to affect the drug release during dissolution testing.

Figure 3 shows a dissolution run of over-encapsulated Erlotinib tablets in HGC shells (40). The capsules were from a group of samples stressed under $40{ }^{\circ} \mathrm{C}$ and
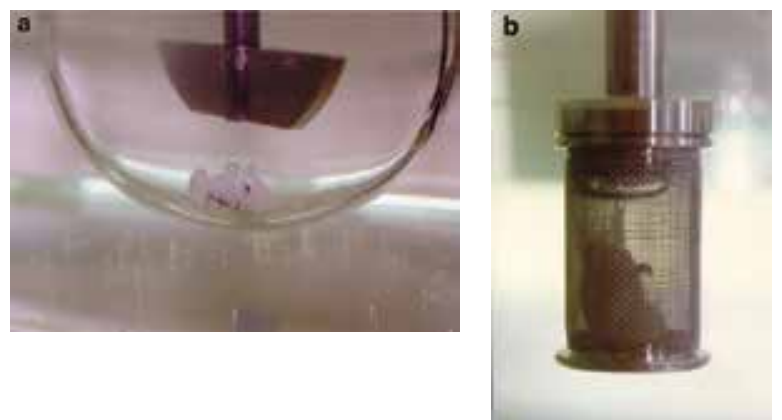

Figure 2. (a) Cross-linked gelatin capsule with sinker in USP Dissolution Appartus 2. (b) Cross-linked gelatin capsule in USP Apparatus 1 (Copyright 2014 Vivian Gray, used by permission.). ${ }^{\circ}$

${ }^{a}$ Marques. AAPS PharmSciTech. 2014, 15 (6), 1410-1416 (44).

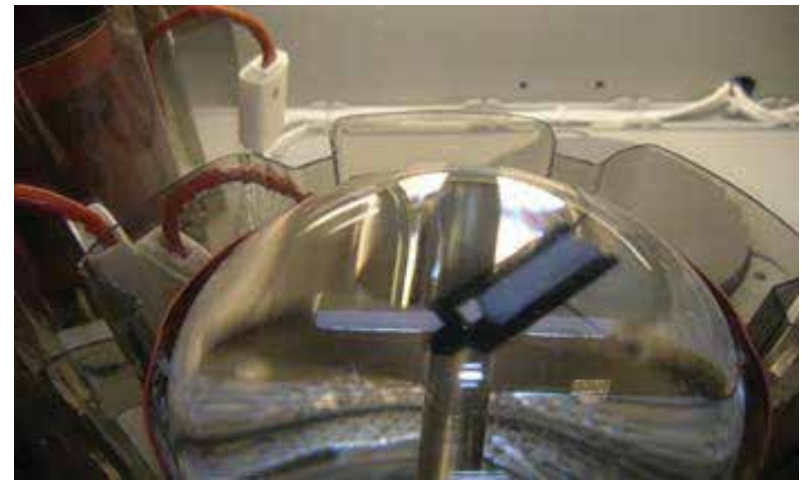

a). Vessel 1, at $2 \mathrm{~min}$

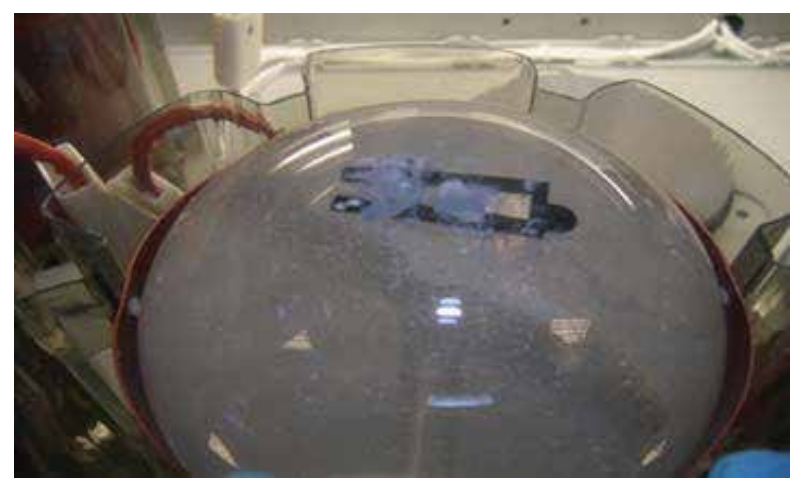

(c). Vessel 1, at $20 \mathrm{~min}$

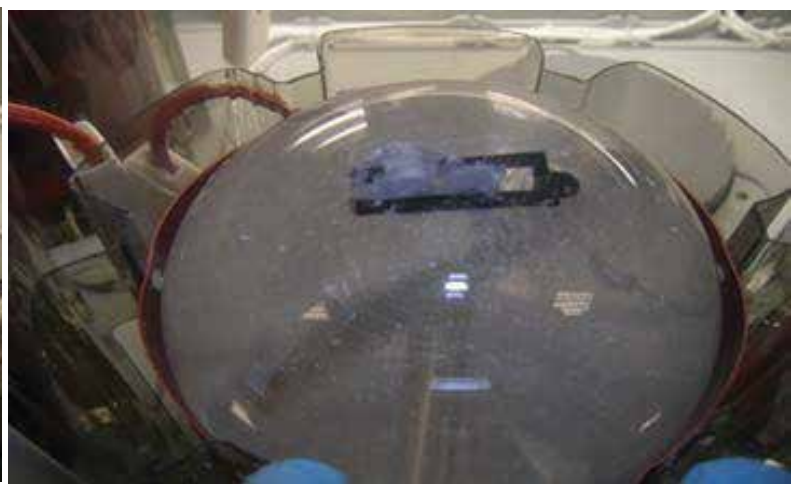

(b). Vessel 1, at $10 \mathrm{~min}$

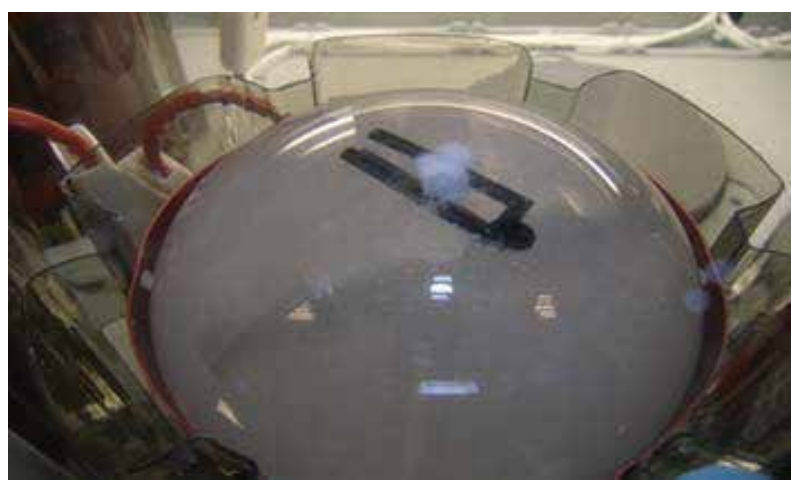

(d). Vessel 1, at $60 \mathrm{~min}$

Figure 3. Observations of the OET dissolution from single-step Tier-1 testing: (a) No change in the capsule shell at 2 minutes. (b) At 10 minutes, the capsule dissolved very slowly; shell covered some of the excipient and drug on the sinker. (c) At 20 minutes, the shell is mixed with excipient and significant amounts remain attached to the sinker; silk-like pieces of shell were visible. (d) At 60 minutes, a piece of shell residue was still visible attached to the sinker. ${ }^{a}$

aLu, et al. J. Pharm. Biomed. Anal. 2011, 56, 23-29 (40). Abbreviations: OET, over-encapsulated tablet. 
high humidity for a week and had failed the dissolution specification. These pictures were taken at dissolution time points of 2,10,20, and 60 minutes during a singlestep Tier-1 dissolution testing. At the 20 minute time point, visible silk-like pieces of gray shell remained and hindered the drug and excipient release. In addition to what has been captured by the pictures, a detailed slow drug release profile was recorded by using in situ UV fiber optics along with detailed visual observations throughout the dissolution testing. The capsule started to break at the jointed end of the sinker at approximately three minutes. The shell then formed a tube-like shape held by the sinker with one open end exposing the filler and tablet. The drug dissolved approximately $4 \%$ at four minutes. A part of the shell started to deform at 5 minutes and turned into stringy gel-like material spinning around the sinker. The solution became cloudy, and the amount of dissolved drug rose to approximately $15 \%$. The remaining capsule dissolved very slowly thereafter. Pieces of the shell still covered some of the drug and filler on the sinker even 35 minutes after the start of the test.

As often noted during dissolution testing, cross-linking is heterogeneous. In the same batch, some capsules can cross-link and some may not. Also, the same capsule can cross-link in just one area, not the entire capsule. For any six capsules from a stability study from a single container, it is possible that only some will exhibit cross-linking; the degree of cross-linking and the level of dissolution slowdown varied among the six capsules tested (40). Therefore, the ways in which to record the observation and describe the phenomenon are critical for fulfilling the USP requirements of cross-linking evidence.

\section{Capsule Switching Test}

A capsule shell switching test is another way to identify gelatin cross-linking (3). For this test, the content of an aged or stressed capsule is fully transferred into a fresh shell; subsequently, the emptied aged capsule shell is filled with a fresh blend of the same formulation. The switched capsules are then subjected to dissolution testing. A comparison of the in vitro dissolution results of the aged capsule shells filled with fresh blend with that of fresh capsules containing aged formulation blend can confirm if the dissolution slowdown of the aged gelatin capsules is due to the change of the property of the capsule shell due to cross-linking. The capsules with either old or fresh blend in fresh capsule shells should both have satisfactory drug release. The samples with fresh drug blend in aged capsule shells may have low drug release, demonstrating crosslinking. During formulation development and dissolution method development, such capsule switching tests combined with lab stability and stressed studies provide valuable information. The test results can prove that the aged or stressed capsule shell, rather than a change in the product (formulation) quality, caused the original dissolution slowdown or failure. In addition to visual observation, the capsule switching test provides another means of detecting gelatin capsule shell cross-linking.

Notonly is the capsule switch test useful in the development stage, but it is also suitable for late-stage and GMP stability studies. When HGC samples from a specific time point stored under specific temperature and humidity conditions fail the specification in a Tier-1 dissolution test, a capsule switching test should be conducted. Although a visual observation of a reluctant capsule shell rupture is a good indication that dissolution failure was most likely caused by cross-linking in the capsule shell rather than drug formulation performance, further investigation using switched capsules and repeated Tier-1 tests would provide evidence of gelatin cross-linking and justify Tier-2 tests using enzymes. It is wise to use multiple samples for the capsule switching test because the degree of cross-linking is not always consistent across all capsules in a given package, and the dissolution slowdown of stability samples is highly variable from capsule to capsule. For example, Cui et al. (41) reported the contents of six capsules stored at the same condition for the same length of time and had dissolution slowdown were fully transferred into six fresh shells. The fresh capsule shells were from the same batch as those used in the stability study but had been wellmaintained at ambient conditions without stress. The six emptied shells were refilled with a fresh drug blend made with the same formula and manufacturing process. The dissolution results confirmed that the shells were the cause of slowed dissolution (41).

Lozano et al. reported another case identifying gelatin cross-linking for an over-encapsulated tablet (OET) in a gelatin capsule formulation (47). The stability sample of the OET at the one-year time point had slowdown drug release in the Tier-1 dissolution test. After switching the aged shells, filler and tablets with fresh ones, the dissolution test was repeated using the same dissolution medium. It was identified that the aged gelatin shell as the root cause of the slowdown due to gelatin crosslinking as shown in Figure 4. A Tier-2 test was subsequently performed for the one-year OET sample by adding pepsin to the medium. Their Tier-2 dissolution results passed the specification.

When considering a capsule switching test to identify gelatin cross-linking, consider that capsule switching 


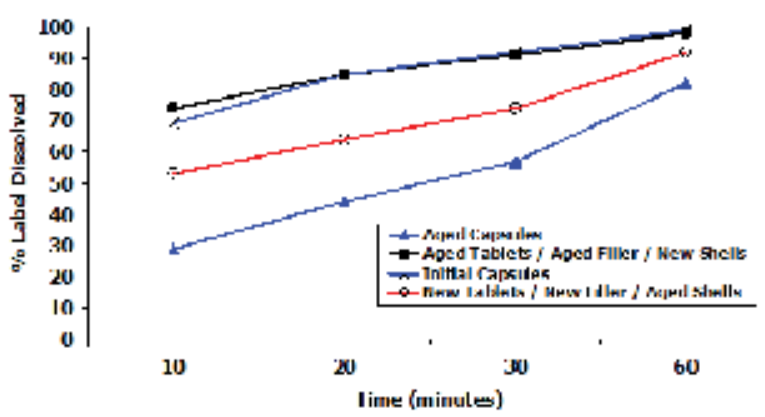

Figure 4. Identification of gelatin capsule cross-linking for an encapsulated tablet in gelatin capsule formulation by conducting capsule switching test in comparison with samples from the aged and stability initial capsules. ${ }^{a}$

${ }^{a}$ Lozano, et al. Am. Pharm. Rev. 2001, 4 (4), 8-16 (47).

testing may not be suitable for all types of gelatin capsules such as SGCs. The capsule switching test is also limited for HGCs depending on the forms of the filling materials and coating considerations. The types of materials for filling into HGCs include dry solids (e.g., powders, pellets, granules or tablets), semisolids (e.g., suspensions or pastes), and liquids (e.g., non-aqueous liquids) $(48,49)$. The switching test can only be conducted in HGCs filled with dry solids without sealing and enteric coatings; the two pieces of an HGC shell must be separated, and the filler must be transferred out.

\section{Spectroscopic Determination}

Instrumental techniques such as various spectroscopies have been applied to evaluate gelatin cross-linking (3, 29). These spectroscopic techniques include NMR, UV, fluorescence spectrophotometry (FS), near infrared (NIR), and Fourier transform-infrared (FT-IR). All these spectroscopic techniques may have been thought naturally suitable in all situations for determining evidence of gelatin cross-linking (44). However, the published cases using spectroscopy were studies to understand the nature and mechanism of gelatin cross-linking using specially treated samples; none were explicitly designed for testing formal stability samples or marketed formulations of HGCs during their shelf storage, and none of the studies were used to justify Tier-2 testing. It is important to take a close look at these spectroscopic techniques in the perspectives of their usefulness and limitations for identifying cross-linking in gelatin capsule shells when the formulations experienced dissolution slowdown due to stress tests in stability studies or a long time storage of marketed formulations.

\section{Carbon-13 Nuclear Magnetic Resonance}

The use of ${ }^{13} \mathrm{C}$-NMR for the study of gelatin-formaldehyde cross-linking was reported as early as 1978 (50). Measuring an extremely low concentration of cross-linking in the presence of a complex heterogeneous polymer containing different types of amino acids is a challenge. Taylor et al. utilized an NMR (Bruker WH-90) and $90 \%{ }^{13} \mathrm{C}$ enriched formaldehyde to study the gelatin cross-linking caused by formaldehyde. They found the major formaldehyde methylene cross-linking in aqueous solutions is formed between lysine and arginine amino acid components in gelatin. Lysine and arginine methylols were involved in the formaldehyde-driven cross-linking reaction.

Another study was conducted by Albert et al. (51) using an NMR tube as well as a circulated NMR flow cell to investigate gelatin-formaldehyde cross-linking. A gelatin sample solution was prepared using inert gelatin powder in distilled water. A hardened gelatin sample was prepared by the further addition of a $30 \%$ formaldehyde solution. When the flow cell was used, gaseous formaldehyde was transferred into a phosphate buffer solution ( $\mathrm{pH}$ 7.2) containing gelatin. The solution was circulated by a tubing pump through the flow cell. Different species formed during the process were investigated by an NMR spectrometer (Bruker WM 400). ${ }^{13} \mathrm{C}$ enriched formaldehyde was used to study the crosslinking reaction with gelatin and its hardening, which lead to methylene and oxymethylene bridges between gelatin amino groups. The hardened gelatin also showed an increase in the number of methylene bridges.

When solid state ${ }^{13} \mathrm{C}$-NMR technology became available, Albert et al. further investigated the hardening reaction of gelatin with ${ }^{13} \mathrm{C}$-labelled formaldehyde and correlated their results with what they obtained from the solution ${ }^{13} \mathrm{C}-\mathrm{NMR}$ (52). When in solution, the formaldehyde reacted with gelatin, formed methylols of lysine residues and, later, arginine residues which reacted and resulted in the formation of lysine-arginine cross-linking. During the drying process for hardened gelatin, an arginine-arginine cross-linking is formed in addition to the lysine-arginine cross-linking (see Figure 5 and 6). The rate of cross-linking formation is strongly influenced by humidity with maximum cross-linking occurring at approximately $60-70 \%$ humidity.

Gold et al. also performed solution ${ }^{13} \mathrm{C}$-NMR studies to investigate formaldehyde-induced cross-linking in gelatin, with a focus on the influence of $\mathrm{pH}$ and the enzyme pancreatin (53). Under alkaline conditions (i.e., pH 7.2 and 13.0), when a $6 \%$ solution of gelatin in water is treated with $2000 \mathrm{ppm}$ or $100 \mathrm{ppm}{ }^{13} \mathrm{C}$-enriched formaldehyde, the unprotonated $\varepsilon$-amino functional group in lysine and the guanidine functional group in arginine reacted with the formaldehyde resulting in cross-linking. ${ }^{3} \mathrm{C}-\mathrm{NMR}$ spectra were obtained by using a Varian VXR-300 spectrometer, which showed peaks representing methylols of arginine and lysine as well as a methylene cross-link between arginine and lysine (see Figure 7). However, the lysine-arginine cross-linking was not detected when gelatin was exposed 


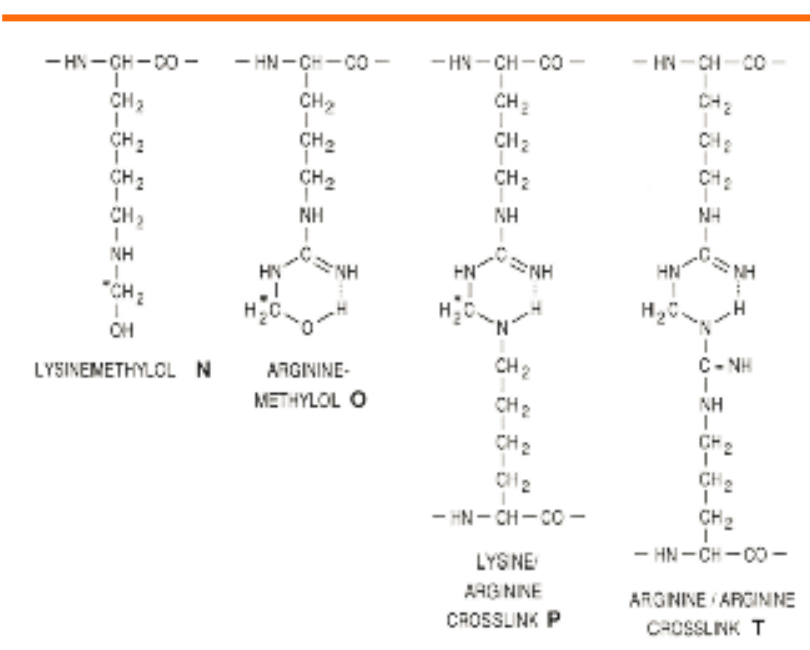

Figure 5. Structure of the main methylols and cross-links formed in the hardening reaction of gelatin and formaldehyde. ${ }^{a}$

${ }^{a}$ Albert, et al. Z. Naturforsch. 1991, 46b, 385-389 (52).

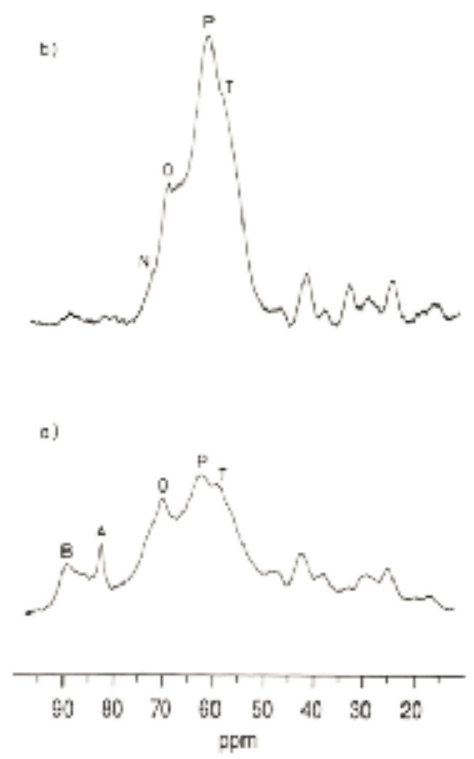

Figure 6. Solid state ${ }^{13} \mathrm{C}-\mathrm{NMR}$ spectra of $12 \%$ gelatin hardened with $0.5 \% 13 \mathrm{C}$ formaldehyde at an air humidity of $60 \%$. Spectra were recorded in two time courses of 2-3 hours (a) and 18-19 hours (b). ${ }^{a}$ ${ }^{a}$ Albert, et al. Z. Naturforsch. 1991, 46b, 385-389 (52).

Labels: A, Formaldehyde-hydrate; B, Formaldehyde dihydrate;

$N$, Lysine methylol; $O$, Arginine methylol; $P$, Lysine-arginine

cross-linking; $T$, Arginine-arginine cross-linking.

to formaldehyde at $\mathrm{pH} 2.0$ under identical conditions. They found that the enzyme pancreatin depolarized the cross-linked gelatin.

${ }^{13} \mathrm{C}$-NMR has played a key role in the understanding of the gelatin cross-linking mechanism and identifying the reaction site of cross-linking in gelatin. As a research tool, it determined the involvement of amino groups in lysinearginine and arginine-arginine cross-linking after the reaction with formaldehyde. However, the use of ${ }^{13} \mathrm{C}-\mathrm{NMR}$ to confirm evidence of cross-linking in dissolution testing for quality control, product release, and stability may not be as simple as what was referred in the literature and the Stimuli to the Revision of USP $<711>(3,44)$. The experimental design, the gelatin treatment, and the testing procedures used from the studies described may not be suitable for directly testing cross-linked gelatin capsule shells. The sensitivity of the ${ }^{13} \mathrm{C}-\mathrm{NMR}$ methodology to determine cross-linking should be assessed carefully. Gold et al. correlate the degree of the cross-linking caused by adding $100 \mathrm{ppm}$ formaldehyde to a $6 \%$ solution of gelatin in water (53). It is still challenging to determine the level of cross-linking that made a drug product in gelatin capsule just fail the USP Tier-1 dissolution test and provide a confirmative evidence of cross-linking as expected by the USP.

(c)

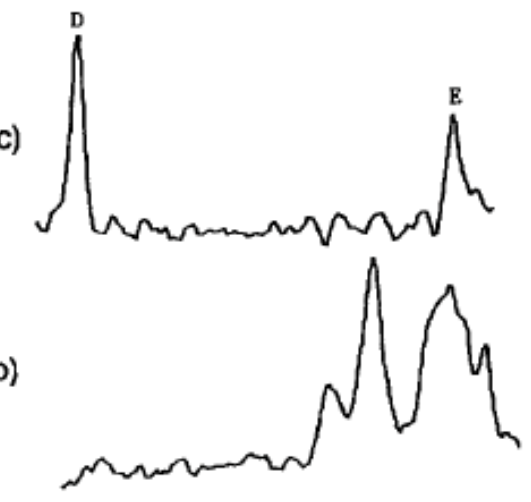

(a)

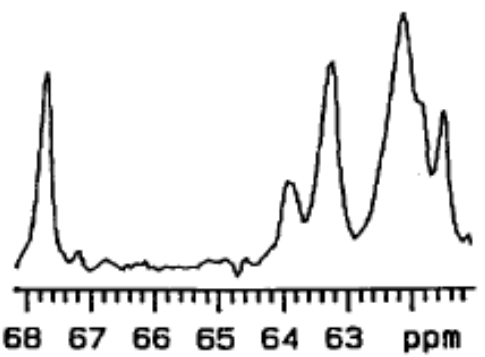

Figure 7. ${ }^{13} \mathrm{C}-\mathrm{NMR}$ spectra of $6 \%$ aqueous gelatin at $\mathrm{pH} 7.2$ with $100 \mathrm{ppm} \mathrm{I} \mathrm{CH}, \mathrm{O}(\mathrm{a}) ; 6 \%$ aqueous unhardened gelatin at $\mathrm{pH} 7.2(\mathrm{~b})$; (c) difference spectrum of cross-linked gelatin (100 ppm) and pure gelatin which was not cross-linked (c). ${ }^{a}$

${ }^{a}$ Gold, et al. Pharm. Dev. Technol. 1996, 1 (1), 21-26 (53).

Labels: D, Arginine methylol; E, Lysine-arginine cross-linking.

Recent advancement in solid state NMR technology and instrumentation has significantly enhanced the capability of solid-state ${ }^{13} \mathrm{C}$-NMR for the quantitative analysis and characterization of complex material and biomolecules (54). Applying solid-state ${ }^{13} \mathrm{C}-\mathrm{NMR}$ to the study of gelatin cross-linking by genipin for drug delivery and formulation evaluation has produced ${ }^{13} \mathrm{C}-\mathrm{NMR}$ spectra with good signal-to-noise ratios and peak assignments (55). The new improvements could be adopted when the ${ }^{13} \mathrm{C}-\mathrm{NMR}$ methodology is further developed to confirm gelatin capsule shell cross-linking. 


\section{Ultra Violet Spectrophotometry}

A UV spectrophotometric method with the use of 2,4,6-trinitrobenzenesulfonic acid (TNBS) as a derivatizing agent with a strong UV chromophore has been applied to evaluate the extent of gelatin cross-linking $(30,56-62)$. This method was originally developed by Okuyama (63) and Satake et al. (64) to determine the free amino groups of amino acids and peptides in column eluates. TNBS reacted specifically and under mild conditions with the primary amine groups of amino acid and peptide in aqueous solution without any undesirable side-reactions (see Figure 8). The resulting trinitrophenyl (TNP) derivatives had a UV absorption with a high molar extinction coefficient at $340 \mathrm{~nm}$. This method was further examined and modified through the years and widely applied to determine free amino groups in proteins (65-70). Kakade and Liener (66) introduced an extraction step which removed both excess unreacted TNBS and TNP- $\alpha$-amino derivatives. This step reduced potential complications from residual TNBS during measurement and allowed the specific determination of $\varepsilon$-amino groups. They also added an autoclave hydrolysis step to assure sample dissolution for spectrophotometric measurements. The UV absorbance was measured at $346 \mathrm{~nm}$ in an acidic $\mathrm{pH}$ to avoid interferences from the sulfite-TNP derivative complex. Bubnis and Ofner (71) further modified the procedure by utilizing an increased TNBS reaction time to allow a complete reaction, which enhanced assay accuracy and reproducibility and made the method more applicable for determining $\varepsilon$-amino groups in a broad range of proteinaceous materials, including cross-linked gelatin. The TNBS/UV assay procedure is described in detail in the literature (71).

The relationship between the absorbance and the moles of $\varepsilon$-amino groups per gram of gelatin was calculated using Equation $1(56,60)$.

\begin{tabular}{|c|c|}
\hline mol of $\varepsilon$-amino groups & $2 \times($ absorbance $) \times(0.020 \mathrm{~L})$ \\
\hline$\overline{\mathrm{g} \text { gelatin }}$ & $\overline{\left(1.46 \times 10^{4} \mathrm{~L} \mathrm{~mol}^{-1} \mathrm{~cm}^{-1}\right) \times(b) \times(x)}$ \\
\hline
\end{tabular}

Where $1.46 \times 10^{4} \mathrm{~L} \mathrm{~mol}^{-1} \mathrm{~cm}^{-1}$ is the molar absorptivity of TNP-lysine, $b$ is the cell path length in $\mathrm{cm}$, and $x$ is the sample weight in grams.

The TNBS/UV assay uses simple devices and can be easily implemented in an analytical laboratory. It generates quantitative results that can be used to determine the level of gelatin cross-linking. The TNBS/UV assay presents a challenge in that sample preparation is laborious and prone to error and variability, and the assay sensitivity can be a limitation. The method was successful when measuring cross-linking at very high level as encountered in those applications using gelatin cross-linking as a tool for product design or drug delivery. However, it may be difficult to determine the low level of cross-linking that caused the gelatin capsule drug products to fail Tier-1 dissolution testing. Ofner et al. (30) used the TNBS/UV assay to study HGC shells filled with lactose mixed with different amounts of formaldehyde. In their report, a $1000 \mathrm{ppm}$ formaldehyde treatment reduced the gelatin $\varepsilon$-amino groups to $83 \%$ of the original uncross-linked value. However, there was no measurable difference between the control capsules (uncross-linked) and those treated with $120 \mathrm{ppm}$ formaldehyde and, by inference, the capsules treated with lower amounts (i.e., 30 and 20 ppm). Only a small measurable loss of $\varepsilon$-amino groups (approximately 3.6\%) was shown for the capsules treated with $200 \mathrm{ppm}$. Another drawback to the TNBS/UV assay is that it only focuses on the $\varepsilon$-amino group, which reflects the cross-linking involving lysine, but cannot detect any cross-linking with other functional groups in combination with, or independent of, $\varepsilon$-amino groups such as arginine (guanidino-functional groups)-to-lysine and arginine-toarginine.

\section{Near-infrared Spectroscopy}

NIR spectroscopy is a fast and non-destructive analytical technique for detecting cross-linking in gelatin. Gold et al. first reported how NIR was used to predict the
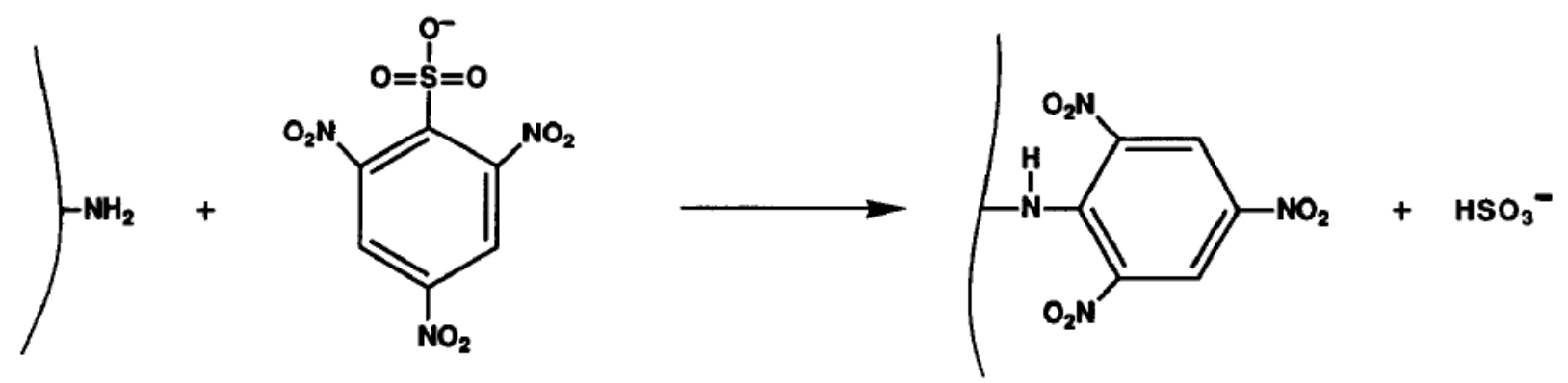

Figure 8. Reaction of 2,4,6-trinitrobenzenesulfonic acid with primary amino groups of protein at an alkaline pH to form a trinitrophenyl derivative and sulfite ion. ${ }^{a}$

${ }^{a}$ Bubnis, et al. Anal. Biochem. 1992, 207, 129-133 (71). 
degree of cross-linking from formaldehyde-stressed HGCs (72). In that study, the HGCs were exposed to a $150 \mathrm{ppb}$ atmosphere of formaldehyde for different durations from 2.25 to 24 hours. The capsules were then filled with fresh amoxicillin, placed in a sample holder, and scanned in an NIR spectrophotometer. The spectra (Figure 9b) were analyzed using principal component regression (PCR). The intact capsules from each experimental group were tested next for dissolution profiles (Figure 9a). The percent of amoxicillin dissolved at 45 minutes was used as a reference to correlate the degree of cross-linking with the spectral data obtained by NIR, which predicted drug dissolution from the intact HGCs with a good linear correlation to the actual dissolution of amoxicillin (Figure 9c).

(a)

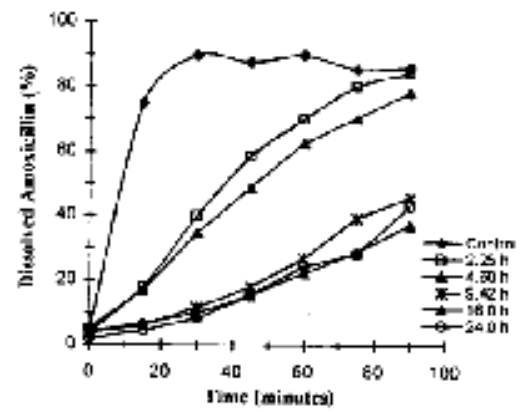

(b)

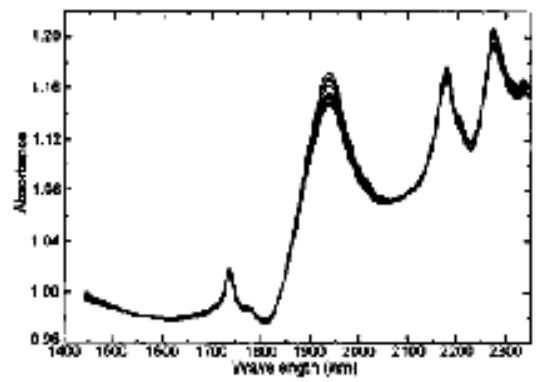

(c)

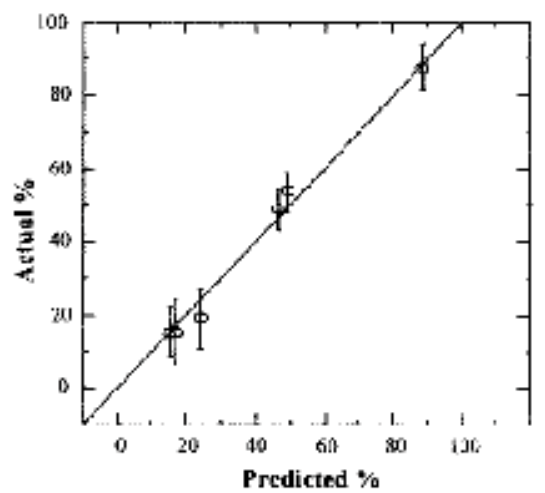

Figure 9. (a) Dissolution curves of amoxicillin ( $\mathrm{pH} 1.2$ medium) from HGCs exposed for various times (0, 2.25, 4.60, 9.42, 16.0, and 24 hours) to 150 ppb formaldehyde atmosphere at ambient temperature. Each point represents the average of six determinations. (b) NIR spectra of $18 \mathrm{HGCs}$, three for each of the six exposure times above. (c) Correlation of the actual dissolution of amoxicillin from HGCs to dissolution predicted from the NIR spectral data. ${ }^{a}$

${ }^{a}$ Gold, et al. Pharm. Dev. Technol. 1998, 3 (2), 209-214. (73).

Abbreviations: HGC, hard gelatin capsule; NIR, near infrared spectroscopy
Gold et al. also applied NIR to soft elastic gelatin capsules (SEGCs) to detect formaldehyde-induced cross-linking (73). In that study, formaldehyde migration from a polyethylene glycol (PEG 400) filled into SEGCs was monitored using NIR spectrophotometry. The capsules were filled with various formaldehyde solutions in PEG 400 (0.05-0.40\% $\mathrm{v} / \mathrm{v}$ ) and stored at ambient conditions for 48 hours. They were then emptied, rinsed, and stored under a nitrogen atmosphere for 24 hours. The treated capsules were scanned in an NIR spectrophotometer. PCR then analyzed the spectra. A linear relationship was found between the spiked concentrations of formaldehyde in the PEG fill of the capsules and the concentrations predicted by the NIR. The same experiment was further evaluated, and the NIR spectral data of the empty and rinsed capsules were analyzed using bootstrap pattern selection modeling (74). Suitable correlations were also confirmed when the actual concentrations of formaldehyde in the PEG filled capsules were regressed against the values predicted by the NIR.

NIR has demonstrated its usefulness to detect gelatin cross-linking in these cases. However, further studies are needed to make the NIR method meet USP expectations. The effect of formaldehyde stress storage was studied, but heat and humidity stressors and their insolubilization of the gelatin shell were not assessed in the study. While the results insolubilization may be the same, the methods of capsule stresses have different chemical mechanisms which need to be studied separately. NIR is sensitive for detecting cross-linking in HGCs and SEGCs after exposing the capsules to a formaldehyde atmosphere or treated with formaldehyde in the capsule fill. These treatments substantially reduced in vitro release of the incorporated drug. However, this method does not identify and quantitate the participation of a specific functional group, unlike the TNBS/UV method (30). In addition, the NIR method relies on PCR or other chemometrics for data analysis. NIR needs a calibration set of samples that cover the range of the cross-linking around the level that causes Tier-2 dissolution test failure. Making or obtaining these calibration samples is challenging. More involvement from the pharmaceutical analysis community along with additional studies are needed to make the NIR method suitable to confirm cross-linking.

\section{Fluorescence Spectroscopy}

The use of intrinsic fluorescence to investigate the change in conformation of cross-linked gelatin gel is a unique application (75). Gelatin cross-linked with glutaraldehyde emits intrinsic blue fluorescence at $415 \mathrm{~nm}$, which was attributed to the formation of dimeric tyrosine (bityrosine) in the cross-linked gelatin. The ratio of the intensity of the 
blue fluorescence at $415 \mathrm{~nm}$ from the bityrosine to that of tyrosine monomer at $305 \mathrm{~nm}$ changes as the conformation of the cross-linked gelatin conformation changes. Unlike those fluorescence methods for gelatin studies utilizing extrinsic fluorophores through derivatization (76), which usually has huge aromatic rings cross-linked to the peptide or protein that inevitably alters the microenvironment and local conformation, the intrinsic fluorescence is from the amino acid residuals within the gelatin protein, like tyrosine and phenylalanine. Dimeric tyrosine was formed when the distance between different segments or triple-helices of the gelatin got close, and two tyrosine units neared each other. The change in the ratio of the intensity of the fluorescence from the bityrosine to that of the monotyrosine reflects the variation in the microenvironment of the tyrosine and conformation of the gelatin.

From the reported study above, the intrinsic fluorescence measurement can be related to the bonding formed between two tyrosine units in the cross-linked gelatin. However, the tyrosine-to-tyrosine linkage is not a wellstudied or reported gelatin cross-linking mechanism. No correlations of such bonding with the dissolution failure have been established. Since only one report has been published on this method (75), further exploration is needed to define its suitability to confirm the evidence required by USP for gelatin cross-linking, which may lead to the identification of different cross-linking mechanisms other than those induced by formaldehyde, heat, light, or humidity.

\section{Fourier Transform Infrared Spectroscopy}

Vibrational spectroscopy is a valuable tool for investigation and identification because it can give detailed information about the formation or loss of specific chemical bonds, structural rearrangements, and other molecular properties of materials. Payne and Veis (77) studied collagen and gelatin solutions using FT-IR spectroscopy for conformational structures of collagen and gelatin solutions. They used a 9-bounces attenuated total reflectance (ATR) cell with resolution enhanced by spectral deconvolution for their study. The IR spectra of the collagen and gelatin solution showed a strong amide I complex of bands at $1650 \mathrm{~cm}^{-1}$, a strong amide II complex at $1560 \mathrm{~cm}^{-1}$, and a set of three weaker bands centered at about $1245 \mathrm{~cm}^{-1}$ representing the amide III vibrational modes. Each of these regions was interesting and showed characteristic changes signaling that a chemical reaction occurred that affected the chemical bonds.

When FT-IR was first applied to determine gelatin crosslinking, Salsa et al. (78) reported the FT-IR measurement during the reaction of an aqueous solution of formaldehyde with gelatin. The gelatin powder was mixed with potassium bromide and pressed into a pellet. Twenty microliters of diluted formaldehyde aqueous solution were drawn over the pellet. The first FT-IR spectrum was recorded less than two minutes after the beginning of the reaction. Nine subsequent FT-IR spectra were recorded for the same pellet at five-minute intervals. PCR analysis was used to interpret the results. The authors determined that the first three principal components (PCs) account for approximately $90 \%$ of the total variance in the spectra. PC\#1 correlated to the lysine-arginine cross-linking, PC\#2 correlated to arginine-methylol, and PC\#3 correlated to lysine-methylol. The cross-linking reaction was initialized by the lysine-methylol formation, followed by the formation of an arginine-methylol link and the eventual origination of lysine-arginine cross-linking.

Tengroth et al. (79) used FT-IR to evaluate cross-linking in aldehyde treated HGCs. These aldehydes including formaldehyde, acetaldehyde, and propionaldehyde are known to cause cross-linking between the amino acid chains of gelatin. The cross-linked gelatin capsule samples were prepared by exposing empty gelatin capsules in desiccators at ambient temperature together with solutions of the aldehyde without contact. The capsules were removed after various times, and brought into contact with the crystal of an ATR accessory for FTIR measurement. The cross-linking mechanisms were analyzed by studying changes in the vibrational bands of the gelatin spectrum. Figure 10 shows the FT-IR spectra of the gelatin capsules after one hour of exposure to the different aldehydes; the authors identified the formation of lysine and arginine methylols associated with the first step of the cross-linking process. The peaks at 800,1020 , and $1095 \mathrm{~cm}^{-1}$ were assigned to the out-of-plane bending of the ring-like formation of arginine methylol, the $\mathrm{C}-\mathrm{O}$ stretch of the lysine methylol, and the C-O stretch of the arginine methylol. These observed spectral changes conform to the reaction intermediates proposed in previous works based on NMR experiments $(52,53)$. Further spectral changes for the capsules exposed to the aldehyde for longer durations were reported to be mostly from unreacted aldehydes absorbed to the gelatin. Only a minor shift of the amide II peak from 1540 to $1536 \mathrm{~cm}^{-1}$ was assigned to cross-linking.

Elmeshad and Darwish (80) studied the effect of crosslinking on hydrochlorothiazide (HCTZ) release in HGCs and utilized FT-IR spectroscopy. HCTZ is known to decompose through hydrolysis to produce formaldehyde and 6-chloro2,4-disulfamoylaniline $(30,81)$. The formaldehyde from 

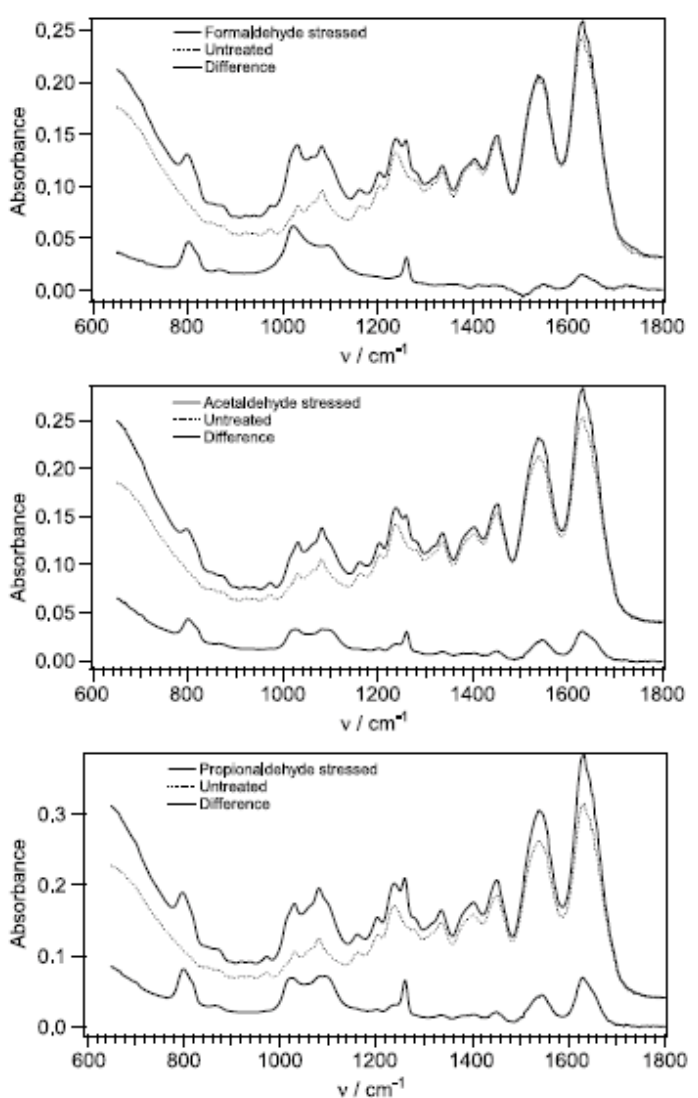

Figure 10. FT-IR spectra of gelatin capsules recorded 24 hours after removal from the desiccator. Each sample is shown together with the spectrum from an untreated gelatin capsule and the difference between the two. The top panel shows the spectrum of the formaldehyde-treated gelatin capsule, the middle panel shows the acetaldehyde-treated gelatin, and the bottom panel shows the spectrum of the propionaldehydehardened gelatin. ${ }^{a}$

${ }^{a}$ Tengroth, et al. Pharm. Dev. Tech. 2005, 10 (3), 405-412 (79). Abbreviations: FT-IR, Fourier transform-infrared spectroscopy.

the API degradation reacts with the amino acid groups in the gelatin shell to form cross-linking and, hence, affect the drug release in dissolution. The FT-IR spectra confirmed the presence of formaldehyde in the four-week stressed $\mathrm{HCTZ}$ capsules with distinguishable spectral peaks. The authors did not attempt to measure the gelatin crosslinking spectra in this work.

The number of reports using FT-IR for gelatin capsule cross-linking is still limited. Many other studies used FT-IR for gelatin and cross-linking but not to evaluate capsule drug release and dissolution, including biomaterial development (81), controlled drug delivery $(55,82)$, nanofiber morphology $(83)$, and food science and packaging applications (62). These studies usually involved the other chemicals or cross-linking reagents. The methodologies, however, including sample preparation, spectral measurement, vibrational band assignment, and data analysis can be adopted to determine cross-linking in gelatin capsules.

\section{CONCLUSIONS}

Following the requirement of the newly revised USP $\langle 711\rangle$, it is important to confirm and document the evidence of cross-linking in gelatin capsule dissolution before proceeding to Tier-2 dissolution tests using enzymes. A review of the existing methodologies used for mechanistic understanding and measuring cross-linking provides a clear picture of the capabilities and limitations of these methodologies.

The visual observation with written or photographic documentation is a direct way to record the phenomenon of cross-linking. However, in most situations, pellicle formation may not be obvious, especially for those moderately or lightly stressed gelatin capsules and those from stability studies when cross-linking starts to form and just starts to affect the drug release in dissolution. In a situation where no standard for recording exists, it is not known if regulatory acceptance would be granted for visual observations.

A capsule switching test is a practical means to confirm cross-linking in conventional HGCs. However, this methodology may not be suitable for SGCs and special types of HGCs, such as liquid or semisolid filled HGCs, enteric coated HGCs, and capsules with sealing that cannot be opened to allow transfer of the capsule contents.

UV spectrophotometry combining the use of TNBS is the only quantitative method so far that can be applied to quantify levels of gelatin cross-linking. This assay requires multiple steps of manual operations and wet chemistry procedures for sample preparation, which may increase the method variability. This assay also carries drawbacks in being able to detect lower levels of cross-linking and crosslinks without the involvement of $\varepsilon$-amino groups.

Other spectroscopic methodologies, including ${ }^{13} \mathrm{C}-\mathrm{NMR}$, FS, NIR, and FT-IR, have demonstrated their usefulness in investigating cross-linking mechanisms. However, their use was always in combination with specially stressed samples. The spectral observation and band intensity correlate with the amount of formaldehyde used for the stressing treatment. More efforts are needed to correlate spectral signal intensity with the Tier-1 dissolution test failure quantitatively or semiquantitatively so that a determination threshold can be established for confirming evidence of cross-linking.

Confirming gelatin cross-linking to meet the USP requirement is not simple. Many practical challenges exist along with the complicated variety of cross-linking mechanisms, non-quantitative and inconsistent (i.e., 
heterogeneous) nature of the evidence, the variabilities in formulations, excipients, levels of stress, experience levels of the analysts. More experimental studies and method development work are necessary to establish an acceptable regulatory, operational procedure.

\section{REFERENCES}

1. <711> Dissolution. In The United States Pharmacopeia and National Formulary USP 37-NF 32; The United States Pharmacopeial Convention, Inc.: Rockville, MD, 2014.

2. <2040> Disintegration and Dissolution of Dietary Supplements. In The United States Pharmacopeia and National Formulary USP 38-NF 33; The United States Pharmacopeial Convention, Inc.: Rockville, MD, 2015; pp 1774-1781.

3. Gray, V. A.; Cole, E.; Riva Toma, J. M. D.; et al. Use of Enzymes in the Dissolution Testing of Gelatin Capsules and Gelatin-Coated Tablets-Revisions to Dissolution <711> and Disintegration and Dissolution of Dietary Supplements <2040>. Dissolution Technol. 2014, 21 (4), 6-19. DOI: 10.14227/DT210414P6.

4. <711> Dissolution. In The United States Pharmacopeia and National Formulary USP 24-NF 19, First Supplement; The United States Pharmacopeial Convention, Inc.: Rockville, MD, 2000; $p$ 2696.

5. Digenis, G. A.; Gold, T. B.; Shah, V. P. Cross-Linking of Gelatin Capsules and Its Relevance to Their In Vitro-In Vivo Performance. J. Pharm. Sci. 1994, 83 (7), 915-921.

6. Adesunloye T. A.; Stach, P. E. Effect of Glycine-citric Acid on the Dissolution Stability of Hard Gelatin Capsules. Drug Dev. Ind. Pharm. 1998, 24 (6), 493-500.

7. Langenbucher, F. Linearization of Dissolution Rate Curves by the Weibull Distribution. J. Pharm. Pharmacol. 1972, 24, 979-981.

8. Khalil, S. A.; Ali, L. M.; Abdel Khalek, M. M. Effects of Ageing and Relative Humidity on Drug Release. I. Chloramphenicol Capsules. Pharmazie. 1974, 29, 36-37.

9. York, P. The Shelf Life of Some Antibiotic Preparations Stored Under Tropical Conditions. Pharmazie. 1977, 32, 101-104.

10. Johnson, D. F.; Mcauley, P. V.; Smith, P. M.; French, J. A. G. The Effects of Storage upon In Vitro and In Vivo Characteristics of Soft Gelatin Capsules Containing Digoxin. J. Pharm. Pharmacol. 1977, 29, 576-578.

11. Chafetz, L.; Hong, W.; Tsilifonis, D. C.; Tylor, A. K.; Philip, J. J. Decrease in the Rate of Capsule Dissolution Due to Formaldehyde from Polysorbate 80 Autooxidation. J. Pharm. Sci. 1984, 73 (8), 1186-1187.

12. Mohamad, H.; Renoux, R.; Aiache, S.; Aiache, J. M.; Sirot, J.; Kantelip, J. P. Investigation of Drug Biopharmaceutical Stability: Application to Capsules of Tetracycline Hydrochloride, Part 2: In Vivo Study. S.T.P. Pharma. 1986, 2, 630-635.

13. Georgarakis, M.; Hatzipantou, P.; Kountourelis, J.E. Effect of Particle Size, Content in Lubricant, Mixing Time, and Storage Relative Humidity on Drug Release from Hard Gelatin Capsules. Drug Dev. Ind. Pharm. 1988, 14 (7), 915-923.

14. Murthy, K. S.; Enders, N. A.; Fawzi, M. B. Dissolution Stability of
Hard-Shell Capsule Products, Part I: The Effect of Exaggerated Storage Conditions. Pharm. Technol. 1989, 13 (3), 72-84.

15. Gouda, H. W.; Moustafa, M. A.; Al-Shora, H. I. Effect of Storage on Nitrofurantoin Solid Dosage Forms. Int. J. Pharm. 1984, 18, 213-215.

16. Guyot, M.; Fawaz, F.; Maury, M. In Vitro Release of Theophylline from Cross-Linked Gelatin Capsules. Int. J. Pharm. 1996, 144, 209-216.

17. Mohamad, H.; Renoux, R.; Aiache, S.; Aiache, J. M.; Sirot, J.; Kantelip, J. P. Investigation of Drug Biopharmaceutical Stability, Part 3: Study of Ampicillin Trihydrate Capsules (In Vitro-In Vivo Investigation). S.T.P. Pharma. 1986, 2 (20-21), 912-917.

18. Dey, M.; Enever, R.; Kraml, M.; Prue, D. G.; Smith, D.; Weierstall, R. The Dissolution and Bioavailability of Etodolac from Capsules Exposed to Conditions of High Relative Humidity and Temperatures. Pharm. Res. 1993, 10 (9), 1295-1300.

19. Brown, J.; Madit, N.; Cole, E. T.; Wilding, I. R.; Cadé, D. The effect of crosslinking on the in vivo disintegration of hard gelatin capsules. Pharm. Res. 1998, 15, 1026-1030.

20. Digenis, G. A.; Sandefer, E. P.; Page, R. C.; Doll, W. J.; Gold, T. B.; Darwazeh, N. B. Bioequivalence Study of Stressed and Unstressed Hard Gelatin Capsules using Amoxycillin as a Drug Marker and Gamma Scintigraphy to Confirm Time and GI Location of In Vivo Capsules Rupture. Pharm. Res. 2000, 17 (5), 572-582.

21. Mohamad, H.; Aiache, J. M.; Renoux, R.; Mougin, P.; Kantelip, J. P. Investigation of Drug Biopharmaceutical Stability. Application to Capsules of Tetracycline Hydrochloride. IV. Complementary In Vivo Investigation. S.T.P. Pharma. 1987, 3 (5), 407-411.

22. Hakata, T.; Sato, H.; Watanabe, Y.; Matsumoto, M. Effect of Storage Temperature on the Physicochemical Properties of Soft Gelatin Capsule Shells. Chem. Pharm. Bull. 1994, 42, 1496-1500.

23. Bottom, C. B.; Clark, M.; Carstensen, J.T. Dissolution Testing of Soft-Shell Capsules - Acetaminophen and Nifedipine. J. Pharm. Sci. 1997, 86 (9), 1057-1061.

24. Murthy, K. S.; Reisch, R. G. J.; Fawzi, M. B. Dissolution Stability of Hard-Shell Capsule Products, Part II: The Effect of Dissolution Test Conditions on In Vitro Drug Release. Pharm. Technol. 1989, $13(6), 53-58$.

25. Dahl, T. C.; Sue, I. L. T.; Yum, A. The Effect of Pancreatin on the Dissolution Performance of Gelatin-Coated Tablets Exposed to High Humidity Conditions. Pharm. Res. 1991, 8 (3), 412-414.

26. Carstensen, J. T.; Rhodes, C. T. Pellicle Formation in Gelatin Capsules. Drug Dev. Ind. Pharm. 1993, 19 (20), 2709-2712.

27. Aikman, M.; Augsburger, L.; Berry, I.; et al. Collaborative Development of Two-Tier Dissolution Testing for Gelatin Capsules and Gelatin-Coated Tablets Using Enzyme-Containing Media. Pharm. Forum. 1998; 24 (5), 7046-7050.

28. Meyer, M. C.; Straughn, A. B.; Mhatre, R. M.; Hussain, A.; Shah, V. P.; Bottom, C. B.; Cole, E. T.; Lesko, L. L.; Mallinowski, H.; Williams, R. L. The Effect of Gelatin Cross-Linking on the Bioequivalence of Hard and Soft Gelatin Acetaminophen Capsules. Pharm. Res. 2000, 17 (8), 962-966. 
29. Singh, S.; Rama Rao, K. V.; Venugopal, K.; Manikandan, R. Alteration in Dissolution Characteristics of Gelatin Containing Formulations. A Review of The Problem, Test Methods, and Solutions. Pharm. Technol. 2002, 26, 36-58.

30. Ofner, C. M.; Zhang, Y. E.; Jobeck, V. C.; Bowman, B. J. Crosslinking Studies in Gelatin Capsules Treated with Formaldehyde and in Capsules Exposed to Elevated Temperature and Humidity. J. Pharm. Sci. 2001; 90 (1), 79-88.

31. Chang, C. K.; Alvarez-Nunez, F. A.; Rinella, J. V.; Magnusson, L. E.; Sued, K. Roller Compaction, Granulation and Capsule Product Dissolution of Drug Formulations Containing a Lactose or Mannitol Filler, Starch, and Talc. AAPS PharmSciTech. 2008; 9 (2), 597-604. DOI: 10.1208/s12249-008-9088-y.

32. Cole, E. T.; Cadé, D.; Benameur, H. Challenges and Opportunities in the Encapsulation of Liquid and Semi-Solid Formulations into Capsules for Oral Administration. Adv. Drug Del. Rev. 2008, 60 (6), 747-756.

33. Elmeshad, A. N.; Darwish, M. K. Stability Studies of the Effect of Crosslinking on Hydrochlorothiazide Release. Drug Discov. Ther. 2009, 3 (3), 136-142.

34. St. Clair, M. J.; Purdie, J.; Hu, Y.; McGeough, P. The Effect of Crosslinking on the In Vitro Disintegration of Hard Gelatin Capsules. J. Pharm. Pharmacol. 2010, 62 (10), 1235-1236.

35. Marchais, H.; Cayzeele, G.; Legendre, J-Y.; Skiba, M.; Arnaud, P. Cross-linking of Hard Gelatin Carbamazepine Capsules: Effect of Dissolution Conditions on In Vitro Drug Release. Eur. J. Pharm. Sci. 2003, 19, 129-132.

36. Gallery, J.; Han, J-H.; Abraham, C. Pepsin and Pancreatin Performance in the Dissolution of Cross-linked Gelatin Capsules from pH 1 to 8. Pharm. Forum. 2004, 30 (3), 1084-1089.

37. Zhao, F.; Malayev, V.; Rao, V.; Hussain, M. Effect of Sodium Lauryl Sulfate in Dissolution Media on Dissolution of Hard Gelatin Capsule Shells. Pharm. Res. 2004, 21 (1), 144-148.

38. Pennings, F. H.; Kwee, B. L. S.; Vromans, H. Influence of Enzymes and Surfactants on the Disintegration Behavior of Cross-linked Hard Gelatin Capsules During Dissolution. Drug Dev. Ind. Pharm. 2006, 32, 33-37.

39. Guzman, M. L.; Marques, M. R. C.; Olivera, M. E.; Stippler, E. S. Enzymatic Activity in the Presence of Surfactants Commonly Used in Dissolution Media, Part 1: Pepsin. Results Pharm. Sci. 2016, 6, 15-19. DOI: 10.1016/j.rinphs.2016.02.002.

40. Lu, X.; Xiao, B.; Lo, L.; Bolgar, M. S.; Lloyd, D. K. Development of a Two-Step Tier-2Dissolution Method for Blinded Overencapsulated Erlotinib Tablets Using UV Fiber Optic Detection. J. Pharm. Biomed. Anal. 2011, 56, 23-29. DOI: 10.1016/j.jpba.2011.04.026.

41. Cui, Y.; Xie, M.; Song, X. Gelatin Capsule Shell Cross-linking. Tier II Dissolution Method Development in the Presence of Sodium Lauryl Sulfate. Pharm. Technol. 2011, 35 (5), 62-68.

42. <711> Dissolution. In The United States Pharmacopeia and National Formulary USP 35-NF 30; The United States Pharmacopeial Convention, Inc.: Rockville, MD, 2012; p 295.

43. Marques, M. R. C. Use of Enzymes in the Dissolution Testing of Gelatin Capsules. Am. Pharm. Rev., 2012 October 2. http://www.
americanpharmaceuticalreview.com/Featured-Articles/122194Use-of-Enzymes-in-the-Dissolution-Testing-of-Gelatin-Capsules/ (accessed June 23, 2017).

44. Marques, M. R. C. Enzymes in the Dissolution Testing of Gelatin Capsules. AAPS PharmSciTech. 2014, 15 (6), 1410-1416.

45. Gray, V. A. Identifying Sources of Error and Variability in Dissolution Calibration and Sample Testing. Am. Pharm. Rev. 2002, 5 (2), 8-13.

46. <1094> Capsules - Dissolution Testing and Related Quality Attributes. In The United States Pharmacopeia and National Formulary USP 37-NF 32; The United States Pharmacopeial Convention, Inc.: Rockville, MD, 2014; p 6047.

47. Lozano, R.; Agorrody, M.; Beraud, B.; Dauphin, J. Gelatin CrossLinking in Capsules and Its Effect on Dissolution. Am. Pharm. Rev. 2001, 4 (4), 8-16.

48. Podczeck. F.; Jones, B. E. Pharmaceutical Capsules, 2nd ed.; Pharmaceutical Press: Grayslake, 2004.

49. Gullipalli, R. P. Soft Gelatin Capsules (Softgels). J. Pharm. Sci. 2010, 99 (10), 4107-4148. DOI: 10.1002/jps.22151.

50. Taylor, S. K.; Davidson, F.; Ovenall, D. W. Carbon-13 Nuclear Magnetic Resonance Studies on Gelatin Crosslinking by Formaldehyde. Photogr. Sci. Eng. 1978, 22 (3), 1433-1436.

51. Albert, K.; Peters, B.; Bayer, E.; Treiber, U.; Zwilling, M. CrossLinking of Gelatin with Formaldehyde: A $13 C$ NMR Study. Z. Naturforsch. 1986, 41b, 351-358.

52. Albert, K.; Bayer, E.; Worsching, A.; Vogele, H. Investigation of the Hardening Reaction of Gelatin with 13C-Labeled Formaldehyde by Solution and Solid-State 13C NMR Spectroscopy. Z. Naturforsch. 1991, 46b, 385-389.

53. Gold, T. B.; Smith, S. L.; Digenis, G. A. Studies on the Influence of $\mathrm{pH}$ and Pancreatin on 13C-Formaldehyde-Induced Gelatin CrossLinks Using Nuclear Magnetic Resonance. Pharm. Dev. Technol. 1996, 1 (1), 21-26.

54. Johnson, R. L.; Schmidt-Rohr, K. Quantitative Solid-state 13C NMR with Signal Enhancement by Multiple Cross Polarization. J. Magn. Res. 2014, 239, 44-49. DOI: 10.1016/j.jmr.2013.11.009.

55. Kawadkar, J.; Jain, R.; Kishore, R.; Pathak, A.; Chauhan, M. K. Formulation and Evaluation of Flurbiprofen-loaded Genipin Crosslinked Gelatin Microspheres for Intra-articular Delivery. J. Drug Targ.2013,21(2), 200-210.DOI:10.3109/1061186X.2012.745549

56. Ofner, C. M.; Bubnis, W. A. Chemical and Swelling Evaluations of Amino Group Cross-Linking in Gelatin and Modified Gelatin Matrices. Pharm. Res. 1996, 13 (12), 1821-1827.

57. Choi, Y. S.; Hong, S. R.; Lee, Y. M.; Song, K. W., Park, M. H., Nam, Y. S. Study on Gelatin-containing Artificial Skin: I. Preparation and Characteristics of Novel Gelatin-Alginate Sponge. Biomaterials. 1999, 20 (5), 409-417.

58. Vandelli, M. A.; Rivasi, F.; Guerra, P.; Forni, F.; Arletti, R. Gelatin Microspheres Crosslinked with D, L-Glyceraldehyde as a Potential Drug Delivery System: Preparation, Characterisation, In Vitro and In Vivo Studies. Int. J. Pharm. 2001, 215, 175-184.

59. Kale, R. N.; Bajaj, A. N. Ultraviolet Spectrophotometric Method for Determination of Gelatin Crosslinking in the Presence of Amino 
Groups. J. Young. Pharm. 2010, 2 (1), 90-94. DOI: 10.4103/09751483.62223.

60. García-Astrain, C.; Gandini, A.; Peña, C.; Algar, I.; Eceiza, A.; Corcuera, M.; Gabilondo, N. Diels-Alder "Click" Chemistry for the Cross-Linking of Furfuryl-Gelatin-Polyetheramine Hydrogels. RSC Adv. 2014, 4, 35578-35587.

61. Davidenko, N.; Schuster, C. F.; Bax, D. V.; Raynal, N.; Farndale, R. W.; Best, S. M.; Cameron, R. E. Control of Crosslinking for Tailoring Collagen-Based Scaffolds Stability and Mechanics. Acta Biomaterialia. 2015, 25, 131-142. DOI: 10.1016/j. actbio.2015.07.034.

62. Wang, W.; Li, C.; Zhang, H.; Ni, Y. Using Liquid Smoke To Improve Mechanical and Water Resistance Properties of Gelatin Films. J. Food Sci. 2016, 81 (5), E1151-E1157. DOI: 10.1111/17503841.13282.

63. Okuyama, T.; Satake, K. On the Preparation and Properties of 2,4,6-Trinitrophenyl-Amino Acids and Peptides. J. Biochem. (Japan), 1960, 47 (4), 454-466.

64. Satake, K.; Okuyama, T.; Ohashi, M.; and Shinoda, T. The Spectrophotometric Determination of Amine, Amino Acid and Peptide with 2,4,6-Trinitrobenzene 1- Sulfonic Acid. J. Biochem. (Japan) 1960, 47 (5), 654-660.

65. Habeeb, A. F. Determination of Free Amino Groups in Proteins By Trinitrobenzenesulphonic Acid. Anal. Biochem. 1966, 14 (3), 328-36.

66. Kakade, M. L.; Liener, I. E. Determination of Available Lysine in Proteins. Anal. Biochem. 1969, 27 (2), 273-280.

67. Goodwin, J. F.; Choi, S. Y. Quantification of Protein Solutions with Trinitrobenzenesulfonic Acid. Clin. Chem. 1970, 16, 24-31.

68. Snyder, S. L.; Sobocinski, P. Z. An Improved 2,4,6-trinitrobenzenesulfonic Acid Method for the Determination of Amines. Anal. Biochem. 1975, 64, 284-8.

69. Hazra, A. K.; Chock, S. P.; Alberts, R. W. Protein Determination with Trinitrobenzene Sulfonate: A Method Relatively Independent of Amino Acid Composition. Anal. Biochem. 1984, 137, 437-43.

70. Cayot, P.; Tainturier, G. The Quantification of Protein Amino Groups by the Trinitrobenzenesulfonic Acid Method: A Reexamination. Anal. Biochem. 1997, 249 (2), 184-200.

71. Bubnis, W. A.; Ofner, C. M. The Determination of E-Amino Group in Soluble and Poorly Soluble Proteinaceous Materials by a Spectrophotometric Method Using Trinitrobenzenesulfonic Acid. Anal. Biochem. 1992, 207, 129-133.

72. Gold, T. B.; Buice, R. G.; Lodder, R. A.; Digenis, G. A. Determination of Extent of Formaldehyde-Induced Crosslinking in Hard Gelatin Capsules by Near Infrared Spectrophotometry. Pharm. Res. 1997, 14 (8), 1046-1050.

73. Gold, T. B.; Buice, R .G.; Lodder, R. A.; Digenis, G. A. Detection of Formaldehyde-induced Crosslinking in Soft Elastic Gelatin Capsules Using Near-Infrared Spectrophotometry. Pharm. Dev. Technol. 1998, 3 (2), 209-214.

74. Moses, J.; Buice, R. G.; Lodder, R. A. Determination of Protein Crosslinking with Bootstrap Pattern Selection and Near Infrared
Spectrophotometry. CPS: analchem/0008002, 2000 (Aug.), 1-5.

75. Liu W. G.; Yao, K. D.; Wang, G. C.; Li, H. X. Intrinsic Fluorescence Investigation on the Change in Conformation of Cross-linked Gelatin Gel During Volume Phase Transition. Polymer. 2000, 41, 7589-7592.

76. Watanabe, K.; Tezuka, Y.; Ishii, T. Configuration Between Reformed Collagen Triple Helices and Artificially Introduced CrossLinks in Gelatin Gels. Macromolecules. 1997, 30 (25), 7910-7913.

77. Payne, K. J.; Veis, A. FTIR Spectroscopy of Collagen and Gelatin Solutions: Deconvolution of the Amide I Band for Conformational Studies. Biopolymers. 1988, 27, 1749-1760.

78. Salsa, T.; Pina, M. E.; Teixeira-Dias, J. J. C. Cross-Linking of Gelatin in the Reaction with Formaldehyde: An FTIR Spectroscopic Study. App. Spectrosc. 1996, 50: 1314-1318.

79. Tengroth, C.; Gasslander, U.; Andersson, F. O.; Jacobsson, S. P. Cross-Linking of Gelatin Capsules with Formaldehyde and Other Aldehydes: An FTIR Spectroscopy Study. Pharm. Dev. Tech. 2005, 10 (3), 405-412.

80. Elmeshad, A. N.; Darwish, M. K. Stability Studies of the Effect of Crosslinking on Hydrochlorothiazide Release. Drug Discov. Ther. 2009, 3 (3), 136-142.

81. Kim, S.; Nimni, M. E.; Yang Z.; Han, B. Chitosan/Gelatin-based Films Crosslinked by Proanthocyanidin. J. Biomed. Mat. Res. Part B: Appl. Biomat. 2005, 75B (2), 442-450.

82. Laha, A.; Yadav, S.; Majumdar, S.; Sharma, C. S. In-vitro Release Study of Hydrophobic Drug Using Electrospun Cross-Linked Gelatin Nanofibers. Biochem. Eng. Journal. 2016, 105, 481-488.

83. Staroszczyk, H.; Sztuka, K.; Wolska, J.; Wojtasz-Paja, A.; Kołodziejska, I. Interactions of Fish Gelatin and Chitosan In Uncrosslinked and Crosslinked with EDC Films: FT-IR Study. Spectrochim. Acta Part A: Mol. Biomol. Spectr. 2014, 117, 707712. DOI: 10.1016/j.saa.2013.09.044. 